Article

\title{
Prognostic Value of Tumor Markers, NSE, CA125 and SCC, in Operable NSCLC Patients
}

\section{Dangfan Yu ${ }^{1, *}$, Kaiqi Du ${ }^{2}$, Taifeng Liu ${ }^{1}$ and Guojun Chen ${ }^{3}$}

1 Department of Nuclear Medicine, Zhejiang Provincial Corps Hospital, Chinese People's Armed Police Force, Jiaxing 314000, China; E-Mail: vip20122013@126.com

2 Department of Thoracic Surgery, Zhejiang Provincial Corps Hospital, Chinese People's Armed Police Force, Jiaxing 314000, China; E-Mail: dukaiqi1111@126.com

3 Department of Laboratory Medicine, Zhejiang Provincial Corps Hospital, Chinese People's Armed Police Force, Jiaxing 314000, China; E-Mail: zlzwanger@126.com

* Author to whom correspondence should be addressed; E-Mail: diadem1982@126.com; Tel.: +86-573-8285-2851; Fax: +86-573-8285-2853.

Received: 20 February 2013; in revised form: 7 April 2013 / Accepted: 14 May 2013 / Published: 27 May 2013

\begin{abstract}
The aim of this study was to investigate the prognostic value of tumor markers in operable non-small cell lung cancer (NSCLC) patients. A total of 481 NSCLC patients were enrolled in the present study. High levels of neuron-specific enolase (NSE), carbohydrate antigen 125 (CA125) and squamous cell carcinoma antigen (SCC) were detected in 306 (63.6\%), $89(18.5 \%)$ and $125(26.0 \%)$ patients, respectively. Seventy-eight of 481 patients died of disease progression, and the median disease-free survival (DFS) and overall survival (OS) were 16.0 and 21.0 months, respectively. The three-year DFS rate was 56.7\%, and the OS rate was $75.3 \%$. For serum NSE, the three-year cumulative DFS rate for the normal and elevated group was $67.7 \%$ and $51.8 \%(p=0.007)$. The OS in patients with high and normal levels of NSE was 34.0 months and 48.0 months, respectively. The median DFS was 46.0 months versus 32.0 months ( $p=0.001$ ), and the OS was 48.0 months versus 44.0 months $(p=0.001)$ in patients with normal and high levels of CA125. For patients with squamous cell carcinoma, the overall survival was significantly shorter in patients with elevated levels of SCC $(p=0.041)$. In the multivariate analysis high levels of NSE, CA125 and clinical stage were significantly correlated with worse prognosis $(p<0.05)$. Patients with all three tumor markers elevated presented the worst prognosis $(p<0.05)$. In our analysis, high levels of preoperative serum NSE and CA125 are correlated with worse survival in operable NSCLC patients.
\end{abstract}


Keywords: tumor marker; CA125; NSE; SCC; lung cancer

\section{Introduction}

Lung cancer is the most common malignant neoplasm in the world. Non-small cell lung cancer (NSCLC) represents $80 \%-85 \%$ of patients diagnosed with lung cancer [1]. Radical surgery has been the standard treatment for many decades. Tumor stage at diagnosis is the most important prognostic factor to predict survival. Unfortunately, the majority of patients are newly diagnosed with NSCLC at a late stage [2], resulting in a high mortality rate. A variety of strategies that adopt a combination of chemotherapy and radiotherapy have been investigated in patients with advanced disease post operation. However, a great deal of patients still experienced disease progression in a short time, exhibiting a five-year survival rate of approximately $15 \%$ [3].

Generally, tumor size detected by imaging or physical examination is considered to be the gold method for evaluating the efficacy of treatment. However, treatment response can't be assessed in operable NSCLC patients, because they don't have measurable masses post operation. Serum tumor biological markers could be taken into account as supplement [4]. However, none of these had been proven to be sufficiently and effectively for clinical use. Most of these markers were somewhat controversial and inconclusive [5]. Neuron-specific enolase (NSE), carbohydrate antigen 125 (CA125) and squamous cell carcinoma antigen (SCC) are three markers commonly regarded as tumor markers in NSCLC. NSE has been widely regarded as a marker of small cell lung cancer [6]. A high level of NSE could be observed in some NSCLC and might be correlated with poor prognosis $[7,8]$. CA125, a mucinous glycoprotein, has been used in the diagnosis and follow-up of ovarian cancer [9,10]. A significant correlation between CA125 and the outcome of NSCLC has been reported [11]. SCC originally obtained from squamous cell carcinoma tissue from the uterine cervix [12] has been proven to be a well-established tumor marker for squamous cell carcinoma [13]. However, many reports discouraged its clinical routine use in NSCLC, due to its low sensitivity $[14,15]$.

In the present study, we designed a retrospective clinical analysis of a total of 481 operable NSCLC patients to investigate the relationship between these three tumor markers and patients' characteristics and prognosis.

\section{Results and Discussion}

\subsection{Patients' Characteristics}

A total of 481 NSCLC patients were enrolled in the present study. The patients' characteristics are summarized in Table 1. According to the criteria of the World Health organization/International Association for the Study of Lung Cancer (WHO/IASLC) classification of lung tumors, 236 were squamous cell carcinoma, 221 were adenocarcinoma and 24 were large cell carcinoma; 27 were well differentiated, 248 were moderately differentiated and 206 were poorly differentiated. There were 336 cases with smoking. In terms of the new IASLC staging system, 217 cases were categorized as stage I, 120 as stage II and 144 as stage III. 
Table 1. Association of tumor marker with parameters of patients with non-small cell lung cancer (NSCLC).

\begin{tabular}{|c|c|c|c|c|c|c|c|c|c|c|}
\hline \multirow{2}{*}{ Variables } & \multirow{2}{*}{ Patient $n(\%)$} & \multicolumn{2}{|c|}{ NSE level } & \multirow[b]{2}{*}{$p$} & \multicolumn{2}{|c|}{ CA125 level } & \multirow[b]{2}{*}{$p$} & \multicolumn{2}{|c|}{ SCC level } & \multirow{2}{*}{$\begin{array}{c}p \\
0.000\end{array}$} \\
\hline & & Normal & High & & Normal & High & & Normal & High & \\
\hline Sex & & & & 0.752 & & & 0.652 & $246(67.6)$ & $118(62.4)$ & \\
\hline Male & $364(75.7)$ & $131(36.0)$ & $233(64.0)$ & & $295(81.0)$ & $69(19.0)$ & & $110(94.0)$ & $7(6.0)$ & \\
\hline Female & $117(24.3)$ & $44(37.6)$ & $73(62.4)$ & & $97(82.9)$ & $20(17.1)$ & & & & \\
\hline Age & & & & 0.206 & & & 0.092 & & & 0.917 \\
\hline$<65$ & $333(69.2)$ & $115(34.5)$ & $218(65.5)$ & & $278(83.5)$ & $55(16.5)$ & & $246(73.9)$ & $87(26.1)$ & \\
\hline$\geq 65$ & $148(30.8)$ & $60(40.5)$ & $88(59.5)$ & & $114(77.0)$ & $34(23.0)$ & & $110(74.3)$ & $38(25.7)$ & \\
\hline Smoking & & & & 0.643 & & & 0.640 & & & 0.000 \\
\hline Never & $145(30.1)$ & $55(37.9)$ & $90(62.1)$ & & $120(82.8)$ & $25(17.2)$ & & $130(89.7)$ & $15(10.3)$ & \\
\hline Ever/Current & $336(69.9)$ & $120(35.7)$ & $216(64.3)$ & & $272(81.0)$ & $64(19.0)$ & & $226(67.3)$ & $110(32.7)$ & \\
\hline Alcohol & & & & 0.403 & & & 0.104 & & & 0.001 \\
\hline Never & $249(48.8)$ & $95(38.2)$ & $154(61.8)$ & & $196(78.7)$ & $53(21.3)$ & & $200(80.3)$ & 49 (19.7) & \\
\hline Ever/Current & $232(48.2)$ & $80(34.5)$ & $152(65.5)$ & & $196(84.5)$ & $36(15.5)$ & & $156(67.2)$ & $76(32.8)$ & \\
\hline Histologic type & & & & 0.835 & & & 0.762 & & & 0.000 \\
\hline Squamous cell & $236(49.1)$ & $84(35.6)$ & $152(64.4)$ & & $195(82.6)$ & $41(17.4)$ & & $128(54.2)$ & $108(45.8)$ & \\
\hline Adenocarcinoma & $221(45.9)$ & $81(36.7)$ & $140(63.3)$ & & $177(80.1)$ & 44 (19.9) & & $209(94.6)$ & $12(5.4)$ & \\
\hline Others & $24(5.0)$ & $10(41.7)$ & $14(58.3)$ & & $20(83.3)$ & $4(16.7)$ & & $19(79.2)$ & $5(20.8)$ & \\
\hline Differentiation & & & & 0.495 & & & 0.021 & & & 0.001 \\
\hline Well & $27(5.6)$ & $12(44.4)$ & $15(55.6)$ & & $25(92.6)$ & $2(7.4)$ & & $22(81.5)$ & $5(18.5)$ & \\
\hline Moderate & $248(51.6)$ & $93(37.5)$ & $155(62.5)$ & & $210(84.7)$ & $38(15.3)$ & & $166(66.9)$ & $82(33.1)$ & \\
\hline Poor & $206(42.8)$ & $70(34.0)$ & $136(66.0)$ & & $157(76.2)$ & $49(23.8)$ & & $168(81.6)$ & $38(18.41)$ & \\
\hline T stage & & & & 0.000 & & & 0.001 & & & 0.039 \\
\hline $\mathrm{T} 1$ & $47(9.8)$ & $24(51.1)$ & $23(48.9)$ & & $43(91.5)$ & $4(8.5)$ & & $41(87.2)$ & $6(12.8)$ & \\
\hline $\mathrm{T} 2$ & $342(71.1)$ & $130(38.0)$ & $212(62.0)$ & & $285(83.3)$ & $57(16.7)$ & & $255(74.6)$ & $87(25.4)$ & \\
\hline $\mathrm{T} 3$ & $57(11.9)$ & $6(10.5)$ & $51(89.5)$ & & $43(75.14)$ & $14(24.6)$ & & $36(63.2)$ & $21(36.8)$ & \\
\hline $\mathrm{T} 4$ & $35(7.3)$ & $15(42.9)$ & $20(57.1)$ & & $21(60.0)$ & $14(40.0)$ & & $24(68.6)$ & $11(31.4)$ & \\
\hline N stage & & & & 0.360 & & & 0.004 & & & 0.223 \\
\hline NO & $251(52.2)$ & $97(38.6)$ & $154(61.4)$ & & $218(86.9)$ & $33(13.1)$ & & $194(77.3)$ & $57(22.7)$ & \\
\hline N1 & $128(26.6)$ & $40(31.3)$ & $88(68.8)$ & & $100(78.1)$ & $28(21.9)$ & & $91(71.1)$ & $37(28.9)$ & \\
\hline $\mathrm{N} 2$ & $102(21.2)$ & $38(37.3)$ & $64(62.7)$ & & $74(72.5)$ & $28(27.5)$ & & $71(69.6)$ & $31(30.4)$ & \\
\hline Clinical stage & & & & 0.092 & & & 0.000 & & & 0.189 \\
\hline I & $217(45.1)$ & $90(41.5)$ & $127(58.5)$ & & $191(88.0)$ & $26(12.0)$ & & $171(78.8)$ & $46(21.2)$ & \\
\hline II & $120(24.9)$ & $36(30.0)$ & $84(70.0)$ & & $97(80.8)$ & $23(19.2)$ & & $84(70.0)$ & $36(30.0)$ & \\
\hline IIIa & $109(22.7)$ & $34(31.2)$ & $75(68.8)$ & & $83(76.1)$ & $26(23.9)$ & & $77(70.6)$ & $32(29.4)$ & \\
\hline $\mathrm{IIIb}$ & $35(7.3)$ & $15(42.9)$ & $20(57.1)$ & & $21(60.0)$ & $14(40.0)$ & & $24(68.6)$ & $11(31.4)$ & \\
\hline
\end{tabular}

Bold values are statistically significant $(p<0.05)$. NSE, neuron-specific enolase; CA125, carbohydrate antigen 125; SCC, squamous cell carcinoma antigen. 


\subsection{Tumor Markers and Patients' Characteristics}

The relationship between patients' characteristics and tumor markers is shown in Table 1 . The median serum level of NSE was $18.4 \mathrm{ng} / \mathrm{mL}(3.4-344.2 \mathrm{ng} / \mathrm{mL})$ for the entire population. Three-hundred and six $(60.0 \%)$ patients had NSE more than or equal to $12.5 \mathrm{ng} / \mathrm{mL}$, defined as high range. There was no significant correlation among NSE and sex, age, smoking status, tumor histologic type and cancer cell differentiation. We detected significant correlation between NSE and T stage $(p=0.000)$. Of the 481 patients analyzed for CA125, 89 patients $(17.5 \%)$ had elevated levels (CA125 $\geq 35 \mathrm{U} / \mathrm{mL})$. The median level of CA125 was $14.4 \mathrm{U} / \mathrm{mL}$ (range: $2.5-460.1 \mathrm{U} / \mathrm{mL}$ ). There was a significant relationship between cancer cell differentiation and CA125 levels $(p=0.021)$. The T stage, $\mathrm{N}$ stage and the clinical stage were also correlated with CA125 $(p<0.05)$. The median level of SCC was $1.00 \mathrm{ng} / \mathrm{mL}(0.3-41.7 \mathrm{ng} / \mathrm{mL})$. There was a statistically significant correlation between SCC and tumor histologic type $(p=0.000)$. A high level of SCC was detected in male patients $(p=0.000)$. However, no difference in SCC levels was detected according to the $\mathrm{N}$ stage and clinical stage $(p>0.05)$.

\subsection{Association of Tumor Markers with Disease-Free Survival and Overall Survival}

In the current study, 78 of 481 patients died of disease progression, and the median DFS and OS were 16.0 and 21.0 months, respectively. The three-year DFS rate was $56.7 \%$, and the OS was rate $75.3 \%$. The median PFS was 46.0 months versus 32.0 months $(p=0.001)$, and the OS was 48.0 months versus 44.0 months $(p=0.001)$ in patients with normal and high levels of CA125 (Figure 1). Similarly, for serum NSE, the three-year cumulative DFS rate for normal and elevated group was $67.7 \%$ and $51.8 \%$ (Figure 2, $p=0.007$ ). The median OS of patients with normal levels and elevated levels was 48.0 months and 34.0 months, respectively. There was a significant difference between these two groups (Figure 2, $p=0.000$ ). The serum levels of SCC were not associated with DFS or OS (Figure $3, p>0.05$ ). However, for patients with squamous cell carcinoma, the overall survival was significantly shorter in patients with elevated levels of SCC (Figure 4, $p=0.041$ ).

Figure 1. Kaplan-Meier disease-free survival curves (A) and overall survival curves (B) according to CA125: patients with high levels of CA125 showed shorter disease-free survival and overall survival.

(A)

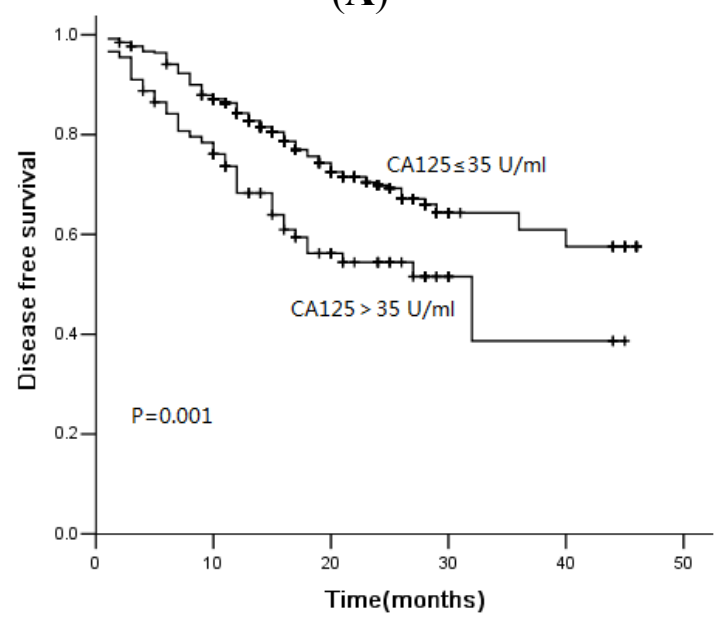

(B)

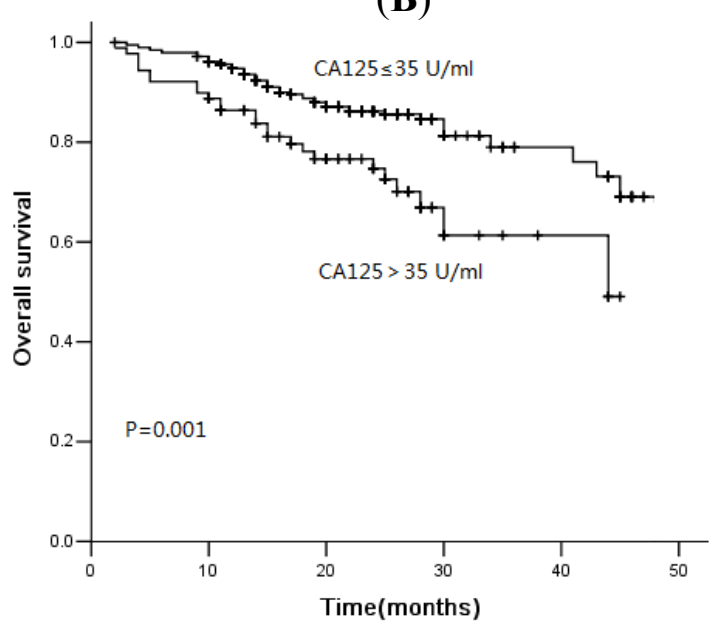


Figure 2. Kaplan-Meier disease-free survival curves (A) and overall survival curves (B) according to NSE: patients with high levels of NSE showed shorter disease-free survival and overall survival.

(A)

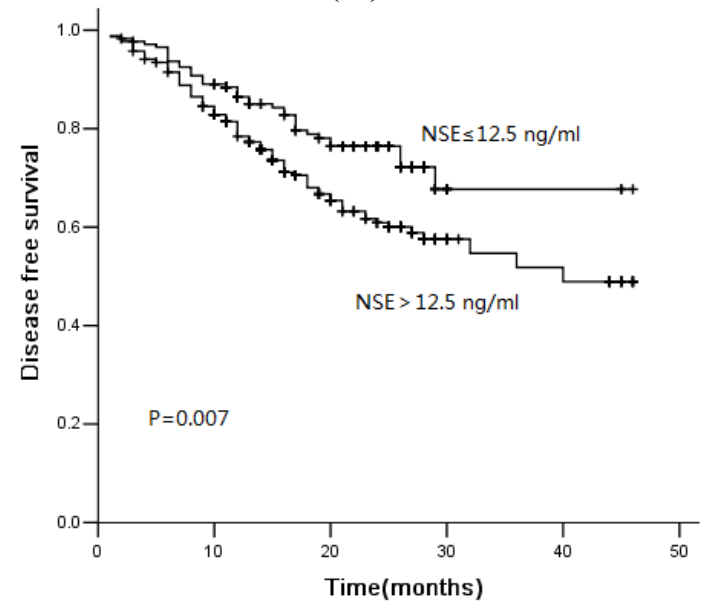

(B)

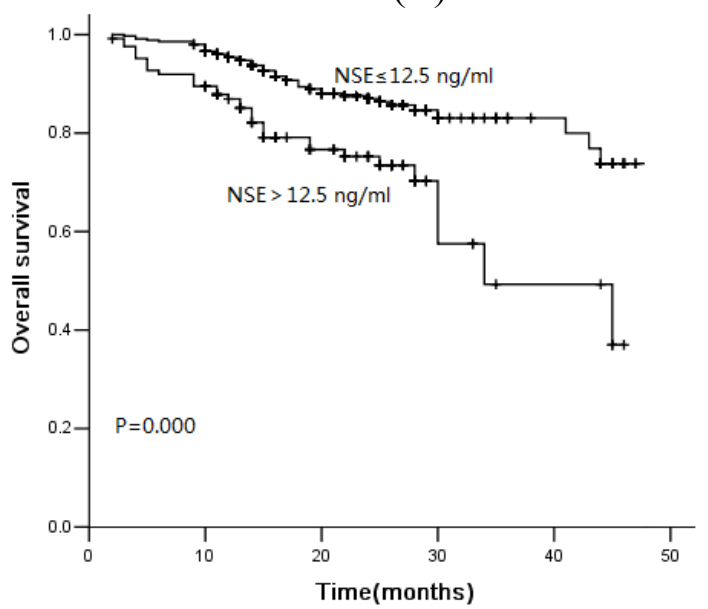

Figure 3. Kaplan-Meier disease-free survival curves (A) and overall survival curves (B) according to SCC: The serum level of SCC was not associated with disease-free survival (DFS) or overall survival (OS).

(A)

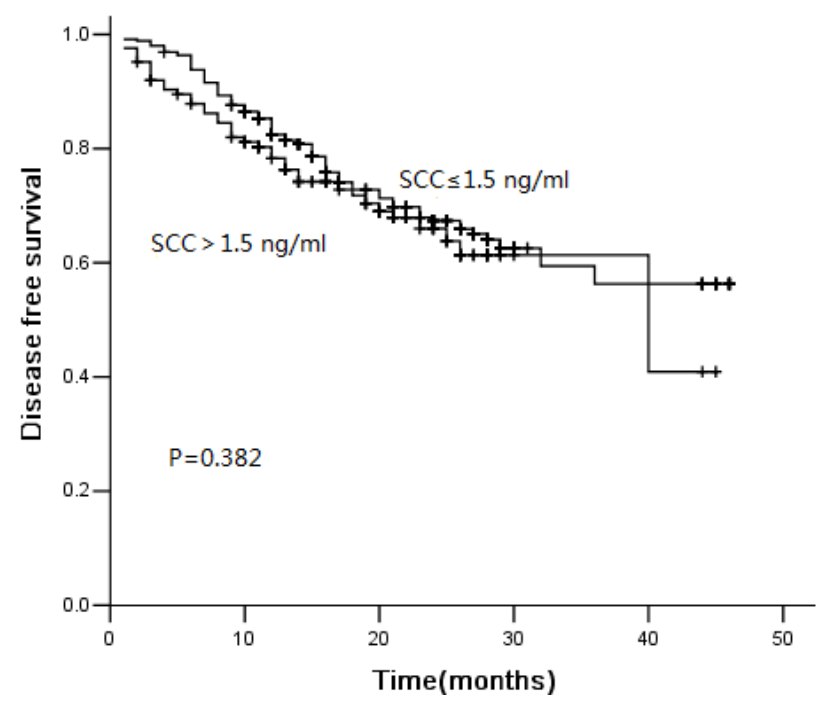

(B)

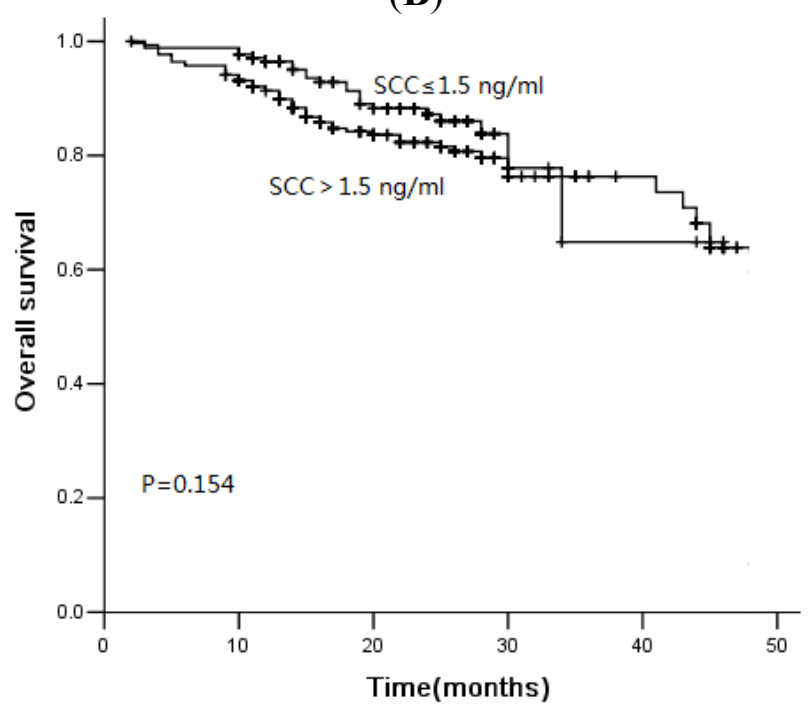

In a multivariable Cox regression model, advanced clinical stage, serum CA125 $\geq 35 \mathrm{U} / \mathrm{mL}$ and serum $\mathrm{NSE} \geq 12.5 \mathrm{ng} / \mathrm{mL}$ were the independent factors associated with significantly unfavorable disease-free survival (Table 2). Furthermore, age $\geq 65$ year, advanced clinical stage, serum CA125 $\geq 35 \mathrm{U} / \mathrm{mL}$ and serum NSE $\geq 12.5 \mathrm{ng} / \mathrm{mL}$ were the independent factors associated with significantly unfavorable overall survival (Table 2). In addition, Cox proportional hazards regression showed that serum SCC was an independent prognostic factor in operable NSCLC. Patients who had serum SCC $\geq 1.5 \mathrm{ng} / \mathrm{mL}$ had an elevated risk of disease progression and death compared with patients who had serum SCC $<1.5 \mathrm{ng} / \mathrm{mL}$. The hazard ratio (HR) was 4.067 (95\% confidence interval [CI], 1.639-10.091) for disease progression 
and 6.909 (95\% CI, 2.167-22.026) for death, and the trend linking increasing fibrinogen levels with risk also was statistically significant for both outcomes $(p<0.05)$ (Table 3$)$.

Figure 4. Kaplan-Meier disease-free survival curves (A) and overall survival curves (B) according to SCC in squamous cell lung cancer: patients with high levels of SCC showed shorter overall survival.

(A)

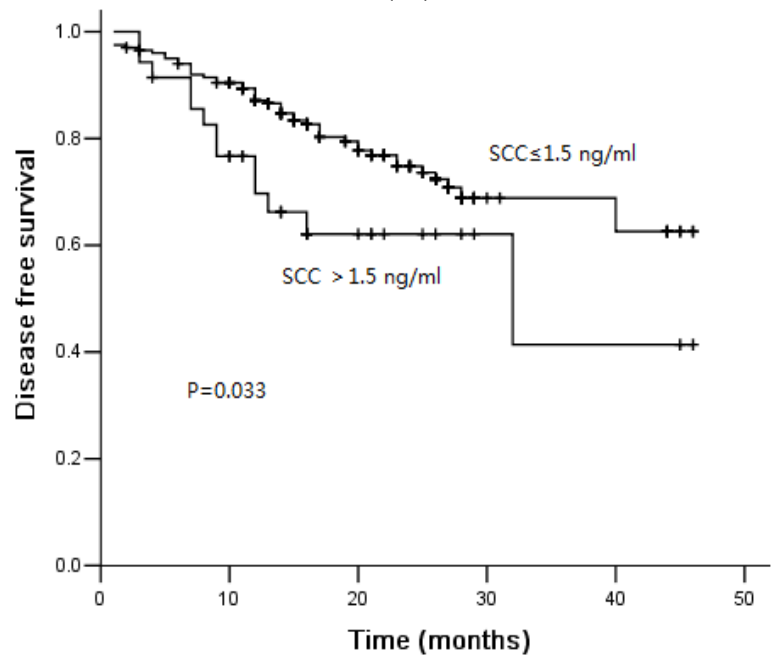

(B)

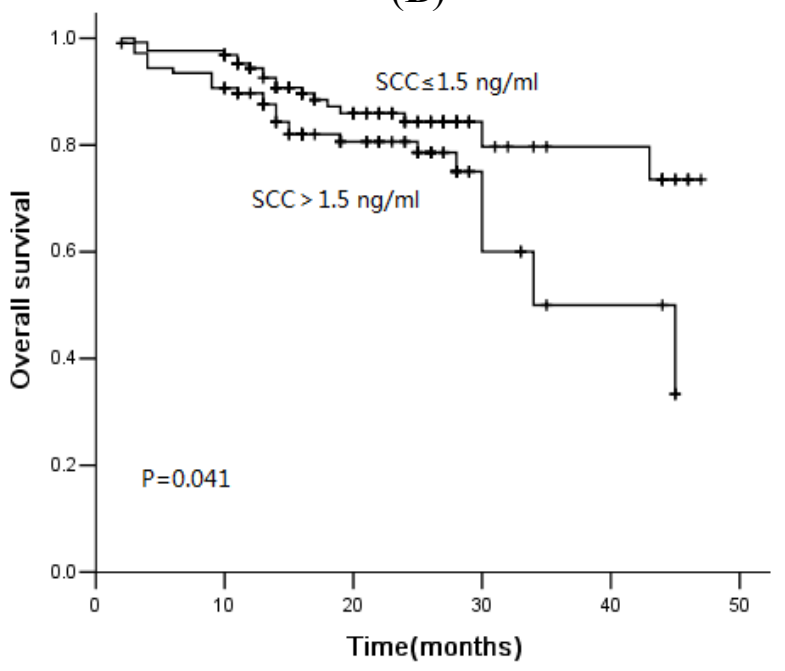

Table 2. Multivariate analysis for disease free survival (DFS) and overall survival (OS) for all patients.

\begin{tabular}{llccc}
\hline End point & \multicolumn{1}{c}{ Parameter } & HR & $\mathbf{9 5 \%}$ CI & $\boldsymbol{p}$ \\
\hline \multirow{2}{*}{ DFS } & Sex: Male $v s$. Female & 1.005 & $0.528-1.914$ & 0.988 \\
& Age: $<65$ Y $v s . \geq 65 \mathrm{Y}$ & 1.379 & $0.971-1.959$ & 0.072 \\
DFS & Smoking: Ever $v s$. Never & 1.030 & $0.573-1.850$ & 0.922 \\
DFS & Clinical stage: I, II $v s$. III & 1.298 & $1.093-1.542$ & $\mathbf{0 . 0 0 3}$ \\
DFS & NSE level: $<12.5 \mathrm{ng} / \mathrm{mL} v s . \geq 12.5 \mathrm{ng} / \mathrm{mL}$ & 1.609 & $1.110-2.333$ & $\mathbf{0 . 0 1 2}$ \\
DFS & CA125 level: $<35 \mathrm{U} / \mathrm{mL} v s . \geq 35 \mathrm{U} / \mathrm{mL}$ & 1.857 & $1.121-2.407$ & $\mathbf{0 . 0 0 6}$ \\
DFS & SCC level: $<1.5 \mathrm{ng} / \mathrm{mL} v s . \geq 1.5 \mathrm{ng} / \mathrm{m}$ & 1.236 & $0.805-1.896$ & 0.333 \\
\hline \multirow{2}{*}{ OS } & Sex: Male $v s$. Female & 0.820 & $0.308-2.180$ & 0.690 \\
& Age: $<65$ Y $v s . \geq 65 \mathrm{Y}$ & 1.676 & $1.051-2.673$ & $\mathbf{0 . 0 3 0}$ \\
OS & Smoking: Ever $v s$. Never & 1.111 & $0.474-2.604$ & 0.808 \\
OS & Clinical stage: I, II $v s$. III & 1.377 & $1.089-1.743$ & $\mathbf{0 . 0 0 3}$ \\
OS & NSE level: $<12.5 \mathrm{ng} / \mathrm{mL} v s . \geq 12.5 \mathrm{ng} / \mathrm{mL}$ & 1.907 & $1.148-3.169$ & $\mathbf{0 . 0 1 3}$ \\
OS & CA125 level: $<35 \mathrm{U} / \mathrm{mL} v s . \geq 35 \mathrm{U} / \mathrm{mL}$ & 2.042 & $1.290-3.225$ & $\mathbf{0 . 0 0 5}$ \\
OS & SCC level: $<1.5 \mathrm{ng} / \mathrm{mL} v s . \geq 1.5 \mathrm{ng} / \mathrm{mL}$ & 1.303 & $0.788-2.157$ & 0.303 \\
\hline
\end{tabular}

Bold values are statistically significant $(p<0.05)$. 
Table 3. Multivariate analysis for disease-free survival (DFS) and overall survival (OS) in squamous cell lung cancer.

\begin{tabular}{llccc}
\hline End point & \multicolumn{1}{c}{ Parameter } & HR & $\mathbf{9 5 \%}$ CI & $\boldsymbol{p}$ \\
\hline \multirow{2}{*}{ DFS } & Sex: Male $v s$. Female & 1.527 & $0.687-3.393$ & 0.299 \\
& Age: $<65$ Y $v s . \geq 65 \mathrm{Y}$ & 1.135 & $0.659-1.955$ & 0.648 \\
DFS & Smoking: Ever $v$ s. Never & 1.764 & $0.786-3.959$ & 0.169 \\
DFS & Clinical stage: I, II $v s$. III & 2.154 & $1.256-3.695$ & $\mathbf{0 . 0 0 5}$ \\
DFS & NSE level: $<12.5 \mathrm{ng} / \mathrm{mL} v s . \geq 12.5 \mathrm{ng} / \mathrm{mL}$ & 1.205 & $0.725-2.004$ & 0.471 \\
DFS & CA125 level: $<35 \mathrm{U} / \mathrm{mL} v s . \geq 35 \mathrm{U} / \mathrm{mL}$ & 1.459 & $0.841-2.531$ & 0.179 \\
DFS & SCC level: $<1.5 \mathrm{ng} / \mathrm{mL} v s . \geq 1.5 \mathrm{ng} / \mathrm{m}$ & 4.067 & $1.639-10.091$ & $\mathbf{0 . 0 0 2}$ \\
\hline \multirow{2}{*}{ OS } & Sex: Male $v s$. Female & 1.609 & $0.395-6.552$ & 0.507 \\
& Age: $<65$ Y $v s . \geq 65 \mathrm{Y}$ & 2.242 & $0.908-5.533$ & 0.080 \\
OS & Smoking: Ever $v s$. Never & 1.857 & $0.443-7.779$ & 0.397 \\
OS & Clinical stage: $\mathrm{I}, \mathrm{II} v s$. III & 2.515 & $1.105-5.723$ & $\mathbf{0 . 0 2 8}$ \\
OS & NSE level: $<12.5 \mathrm{ng} / \mathrm{mL} v s . \geq 12.5 \mathrm{ng} / \mathrm{mL}$ & 2.007 & $0.804-5.012$ & 0.136 \\
OS & CA125 level: $<35 \mathrm{U} / \mathrm{mL} v s . \geq 35 \mathrm{U} / \mathrm{mL}$ & 0.715 & $0.300-1.706$ & 0.450 \\
OS & SCC level: $<1.5 \mathrm{ng} / \mathrm{mL} v s . \geq 1.5 \mathrm{ng} / \mathrm{mL}$ & 6.909 & $2.167-22.026$ & $\mathbf{0 . 0 0 1}$ \\
\hline
\end{tabular}

Bold values are statistically significant $(p<0.05)$.

We analyzed the prognostic value of combination of these three tumor markers. We observed that in this study, 20 patients (4.2\%) presented three elevated markers, 116 patients $(24.1 \%)$, two elevated markers, and 117 patients (24.3\%) three normal markers. We compared DFS and OS between these four groups. Patients with three elevated markers proved to have a significantly shorter DFS and OS (Figure 5, $p<0.05$ ).

Figure 5. Kaplan-Meier disease-free survival curves (A) and overall survival curves (B) according to the score number of three tumor markers combined.

(A)

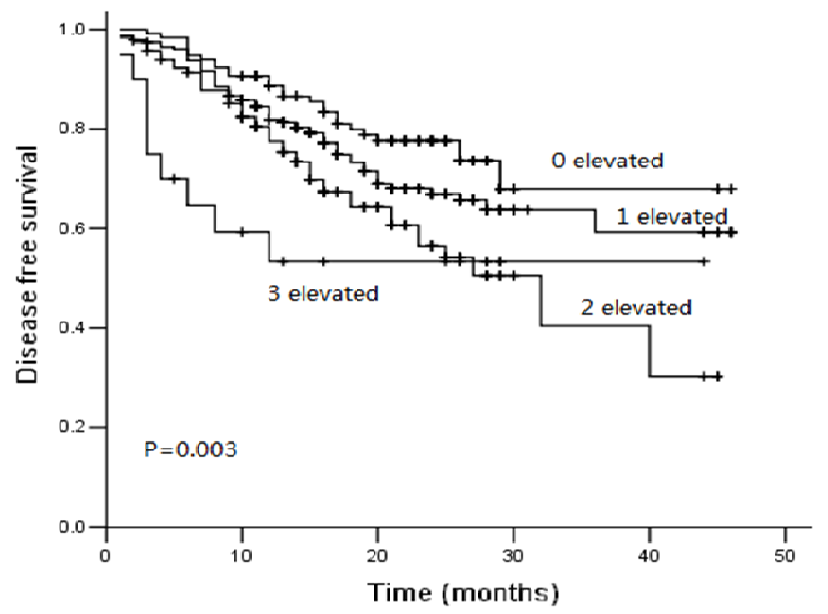

(B)

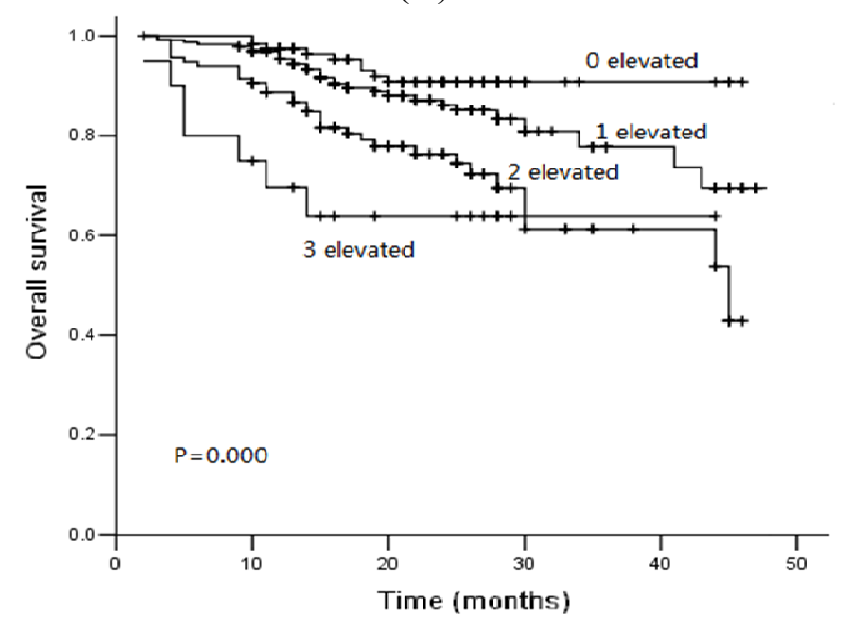

\subsection{Discussion}

Tumor markers are frequently used in clinical practice. However, no serum tumor marker is both sensitive and specific for NSCLC. The results in the present study indicated that pre-operative serum 
NSE levels could be used as a biomarker for outcome prediction in non-small cell lung cancer. Elevated serum NSE levels were correlated with worse prognosis in NSCLC patients. To the best of our knowledge, this is the largest sample report to reveal a correlation between serum NSE levels and the prognosis of operable NSCLC patients.

Although the prognostic value of NSE in SCLC had been widely accepted [16,17], the value in NSCLC was controversial. In the Pujol et al. study with 621 all stages NSCLC patients (majority local advanced or metastatic NSCLC), NSE was a prognostic factor for survival [18]. Similar results were found by other studies, but the sample of the study was relatively small [19,20]. In 231 patients with brain metastasis, elevated NSE levels were found to be a prognostic determinant for overall survival [21]. In our study, high serum NSE levels were correlated with worse prognosis in NSCLC patients, consistent to the results in these studies. However, in the study from Reinmuth et al. [22], with 67 operable early stage NSCLC patients, preoperative serum NSE levels were not associated with prognosis.

The prognostic role of CA125 in NSCLC was not elucidated. Díez M. et al. [23] once reported that preoperative serum CA125 levels were related with TNM stage in operable NSCLC and could provide additional prognostic information. Serum CA125 levels were found to be a tool to monitor the tumor recurrence and disseminated failure post operation [24]. Similar results were found by other authors [25,26]. However, in some case, elevated serum CA125 did not relate with tumor recurrence [27]. In our present study, elevated serum CA125 levels were associated with tumor cell differentiation, TNM stage and survival. Furthermore, in a multivariable Cox regression model, CA125 was found to be an independent factor associated with survival.

Many clinicians investigated the value of SCC in the clinical management of NSCLC patients. In the study of Foa et al. [28] with 62 resectable NSCLC, serum SCC levels have good prognostic ability. Mizuguchi and colleagues [29] have examined the prognostic role of serum SCC levels in stage I NSCLC patients and draw a conclusion that SCC levels were significantly associated with survival. However, in the multivariate analysis, serum SCC levels were not independent prognostic factors. Furthermore, not all studies were consistent with the results in these studies. In two small sample studies [22,30], a lack of association between serum SCC levels and prognosis was observed. In our study with 510 operable NSCLC patients, serum SCC levels were not correlated with survival. However, in squamous cell lung cancer patients, serum SCC levels paly a strong prognostic role.

Despite extensive studies describing the role of tumor markers in the diagnosis of NSCLC, most results still remain debated. None of these biomarkers are mature enough to be routinely used in clinical practice. Combining many tumor biomarkers appropriately increases sensitivity and helps with the diagnosis of NSCLC [31]. Chiu et al. reported that the change in tumor markers (combination of carcinoembryonic antigen (CEA), CA125 and CA199), before and after gefitinib-based chemotherapy, was closely related to the tumor response and progression-free survival [32]. However, in early stage NSCLC, the value of NSE, CA125 and SCC was limited, even a combination of these three markers [33]. Serum CEA might be another promising tumor marker for NSCLC [34]. The use of tumor marker scores, including CEA, might possibly be an important approach in diagnosis and predicting the outcome of NSCLC [35].

There are some limitations in our present study. In this study, we did not consecutively investigate the serum tumor markers' levels post operation and during the follow-up or for the recurrence assessment. 
The relationship between changes in tumor markers and tumor progression need to be investigated. Second, our study included a comparative homogeneous population with the majority of male and smoker patients, which might cause a bias. Also, this is a retrospective study based on patients of one center and could not completely avoid selection bias.

The recent advances in molecular biology have led to understanding the genetics of lung cancer and predicting the outcome of lung cancer patients. The roles of these biologic markers during diagnosis, treatment and follow-up have been the subject of extensive studies recently [36]. Evaluation of these tumor markers might be an earliest clue to tumor progression and may provide the possibility of treatment. The results of our study showed that high levels of preoperative serum NSE and CA125 are correlated with worse survival in operable NSCLC patients. NSE, CA125 and SCC, when measured pre-operation, may provide additional information for prognosis of patients with NSCLC.

\section{Experimental Section}

\subsection{Patients and Treatment}

The present study enrolled 481 patients who had been diagnosed as having non-small cell lung cancer, between 2006 and 2009, at Zhejiang Provincial Corps Hospital, China. All patients had bad been newly confirmed as NSCLC, without previous treatment. Patients with previous or coexisting cancer other than NSCLC were excluded from this study. The study population had a median age of 60 years (range: 37 to 82 years). The patients comprised of $364(75.7 \%)$ males and $117(24.3 \%)$ females. Approval for the present study was obtained from the institutional review board of the hospital. All patients provided informed consent prior to undergoing surgery.

All patients experienced surgery. Lobectomy, bilobectomy or pneumonectomy was performed according to the location or size of lung neoplasm. Systematic mediastinum lymph node dissection was performed in all patients. 223 patients were treated with adjuvant platinum-based chemotherapy or adjuvant radiotherapy or a combination of the two. Detailed information about patient's characteristics and tumor histopathology was collected retrospectively from the medical records.

\subsection{Tumor Markers Measurement}

A blood sample was obtained by peripheral venous puncture, taken before breakfast, 3 days prior to the surgery. Serum levels of NSE, CA125 and SCC were measured by enzyme-linked immunosorbent assay (ELISA). According to the manufacturer's instructions and previously published results $[11,13,18]$, the upper limits of the normal values were at $12.5 \mathrm{ng} / \mathrm{mL}$ for NSE, $35 \mathrm{U} / \mathrm{mL}$ for CA125 and $1.5 \mathrm{ng} / \mathrm{mL}$ for SCC.

\subsection{Follow- Up}

All patients received standardized follow-up, occurring at a 3 month interval for two years, a 6 month interval the third year and yearly thereafter. Evaluation comprised a physical examination, complete blood count, chest computed tomography (CT), brain magnetic resonance imaging (MRI) and abdominal ultrasound. Local recurrence and distance metastasis was histologically confirmed whenever possible. 


\subsection{Statistical Analysis}

The chi-square test was performed to evaluate the association between clinicopathological variables and tumor markers. Disease-free survival (DFS) was defined from the date of definitive surgery to the date of local or distant progression, death of any cause or the date of last follow-up. Overall survival (OS) was calculated as the time from pulmonary surgery to death or censoring. Kaplan-Meier curves were used to estimate the distribution of DFS and OS, and a two-sided log-rank test was performed to compare the difference between survival curves. We used the Cox proportional hazards model with the backward selection method for multivariate analysis. All factors with effects on DFS and OS in univariate analysis $(p \leq 0.10)$ were included in the multivariate analysis. All statistical calculations were performed with SPSS 13.0 for Windows (Chicago, IL, USA). A $p$-value of less than 0.05 was considered statistically significant.

\section{Conclusions}

In summary, preoperative serum NSE and CA125 levels could help us predict the prognosis of NSCLC patients. Further, a large and prospective study is needed to warrant this.

\section{Conflict of Interest}

The authors declare no conflict of interest.

\section{References}

1. Siegel, R.; Naishadham, D.; Jemal, A. Cancer statistics, 2012. CA Cancer J. Clin. 2012, 62, 10-29.

2. Govindan, R.; Bogart, J.; Vokes, E.E. Locally advanced non-small cell lung cancer: The past, present, and future. J. Thorac. Oncol. 2008, 3, 917-928.

3. Miller, Y.E. Pathogenesis of lung cancer: 100 year report. Am. J. Respir. Cell Mol. Biol. 2005, 33, 216-223.

4. Barak, V.; Holdenrieder, S.; Nisman, B.; Stieber, P. Relevance of circulating biomarkers for the therapy monitoring and follow-up investigations in patients with non-small cell lung cancer. Cancer Biomark. 2010, 6, 191-196.

5. Holdenrieder, S.; Nagel, D.; Stieber, P. Estimation of prognosis by circulating biomarkers in patients with non-small cell lung cancer. Cancer Biomark. 2010, 6, 179-190.

6. Jorgensen, L.G.; Hansen, H.H.; Cooper, E.H. Neuron specific enolase, carcinoembryonic antigen and lactate dehydrogenase as indicators of disease activity in small cell lung cancer. Eur. J. Cancer Clin. Oncol. 1989, 25, 123-128.

7. Petrovic, M.; Baskic, D.; Bankovic, D.; Ilic, N. Neuroendocrine differentiation as an indicator of chemosensitivity and prognosis in nonsmall cell lung cancer. Biomarkers 2011, 16, 311-320.

8. Wang, Y.; Tang, D.; Sui, A.; Jiao, W.; Luo, Y.; Wang, M.; Yang, R.; Wang, Z.; Shen, Y. Prognostic significance of NSE mRNA in advanced NSCLC treated with gefitinib. Clin. Transl. Oncol. 2013, 15, 384-390. 
9. Nagele, F.; Petru, E.; Medl, M.; Kainz, C.; Graf, A.H.; Sevelda, P. Preoperative CA 125: An independent prognostic factor in patients with stage I epithelial ovarian cancer. Obstet Gynecol. 1995, 86, 259-264.

10. Bast, R.C., Jr.; Badgwell, D.; Lu, Z.; Marquez, R.; Rosen, D.; Liu, J.; Baggerly, K.A.; Atkinson, E.N.; Skates, S.; Zhang, Z.; et al. New tumor markers: CA125 and beyond. Int. J. Gynecol. Cancer 2005, 15, 274-281.

11. Cedres, S.; Nunez, I.; Longo, M.; Martinez, P.; Checa, E.; Torrejón, D.; Felip, E. Serum tumor markers CEA, CYFRA21-1, and CA-125 are associated with worse prognosis in advanced non-small-cell lung cancer (NSCLC). Clin. Lung Cancer 2011, 12, 172-179.

12. Kato, H.; Morioka, H.; Tsutsui, H.; Aramaki, S.; Torigoe, T. Value of tumor-antigen (TA-4) of squamous cell carcinoma in predicting the extent of cervical cancer. Cancer 1982, 50, 1294-1296.

13. Kagohashi, K.; Satoh, H.; Ishikawa, H.; Ohtsuka, M.; Sekizawa, K. A re-evaluation of squamous cell carcinoma antigen (SCC) as a serum marker for non-small cell lung cancer. Med. Oncol. 2008, 25, 187-189.

14. Niklinski, J.; Furman, M.; Laudanski, J.; Kozlowski, M. Evaluation of squamous cell carcinoma antigen (SCC-Ag) in the diagnosis and follow-up of patients with non-small cell lung carcinoma. Neoplasma 1992, 39, 279-282.

15. Moro, D.; Villemain, D.; Vuillez, J.P.; Delord, C.A.; Brambilla, C. CEA, CYFRA21-1 and SCC in non-small cell lung cancer. Lung Cancer 1995, 13, 169-176.

16. Schneider, J.; Philipp, M.; Salewski, L.; Velcovsky, H.G. Pro-gastrin-releasing peptide (ProGRP) and neuron specific enolase (NSE) in therapy control of patients with small-cell lung cancer. Clin. Lab. 2003, 49, 35-42.

17. Pujol, J.L.; Quantin, X.; Jacot, W.; Boher, J.M.; Grenier, J.; Lamy, P.J. Neuroendocrine and cytokeratin serum markers as prognostic determinants of small cell lung cancer. Lung Cancer 2003, 39, 131-138.

18. Pujol, J.L.; Boher, J.M.; Grenier, J.; Quantin, X. Cyfra 21-1, neuron specific enolase and prognosis of non-small cell lung cancer: Prospective study in 621 patients. Lung Cancer 2001, 31, 221-231.

19. Barlesi, F.; Gimenez, C.; Torre, J.P.; Doddoli, C.; Mancini, J.; Greillier, L.; Roux, F.; Kleisbauer, J.P. Prognostic value of combination of Cyfra 21-1, CEA and NSE in patients with advanced non-small cell lung cancer. Respir. Med. 2004, 98, 357-362.

20. Nisman, B.; Heching, N.; Biran, H.; Barak, V.; Peretz, T. The prognostic significance of circulating neuroendocrine markers chromogranin a, pro-gastrin-releasing peptide and neuron-specific enolase in patients with advanced non-small-cell lung cancer. Tumour. Biol. 2006, 27, 8-16.

21. Jacot, W.; Quantin, X.; Boher, J.M.; Andre, F.; Moreau, L.; Gainet, M.; Depierre, A.; Quoix, E.; Chevalier T.L.; Pujol, J.L. Association d'Enseignement et de Recherche des Internes en Oncologie. Brain metastases at the time of presentation of non-small cell lung cancer: A multi-centric AERIO analysis of prognostic factors. Br. J. Cancer 2001, 84, 903-909.

22. Reinmuth, N.; Brandt, B.; Semik, M.; et al. Prognostic impact of Cyfra21-1 and other serum markers in completely resected non-small cell lung cancer. Lung Cancer 2002, 36, 265-270. 
23. Diez, M.; Torres, A.; Maestro, M.L.; Ortega, M.D.; Gómez, A.; Pollán, M.; Lopez, J.A.; Picardo, A.; Hernando, F.; Balibrea, J.L. Prediction of survival and recurrence by serum and cytosolic levels of CEA, CA125 and SCC antigens in resectable non-small-cell lung cancer. $B r . J$. Cancer 1996, 73, 1248-1254.

24. Diez, M.; Gomez, A.; Hernando, F.; Ortega, M.D.; Gómez, A.; Pollán, M.; Lopez, J.A.; Picardo, A.; Hernando, F.; Balibrea, J.L. Serum CEA, CA125, and SCC antigens and tumor recurrence in resectable non-small cell lung cancer. Int. J. Biol. Markers 1995, 10, 5-10.

25. Hatzakis, K.D.; Froudarakis, M.E.; Bouros, D.; Tzanakis, N.; Karkavitsas, N.; Siafakas, N.M. Prognostic value of serum tumor markers in patients with lung cancer. Respiration 2002, 69, 25-29.

26. Gaspar, M.J.; Diez, M.; Rodriguez, A.; Ratia, T.; Martin, D.A.; Galvan, M.; Granell, J.; Coca, C. Clinical value of CEA and CA125 regarding relapse and metastasis in resectable non-small cell lung cancer. Anticancer Res. 2003, 23, 3427-3432.

27. Nuñez, G.R.; Ito, C.; Del Giglio, A. Increased serum CA-125 levels in patients with lung cancer post thoracotomy. South Med. J. 2009, 102, 427-428.

28. Foa, P.; Fornier, M.; Miceli, R.; Seregni, E.; Santambrogio, L.; Nosotti, M.; Massaron, S.; Cataldo, I.; Oldani, S.; Iurlo, A.; et al. Preoperative CEA, NSE, SCC, TPA and CYFRA 21.1 serum levels as prognostic indicators in resected non-small cell lung cancer. Int. J. Biol. Markers 1999, 14, 92-98.

29. Mizuguchi, S.; Nishiyama, N.; Iwata, T.; Nishida, T.; Izumi, N.; Tsukioka, T.; Inoue, K.; Uenishi, T.; Wakasa, K.; Suehiro, S. Serum Sialyl Lewis x and cytokeratin 19 fragment as predictive factors for recurrence in patients with stage I non-small cell lung cancer. Lung Cancer 2007, 58, 369-375.

30. Foa, P.; Fornier, M.; Miceli, R.; Seregni, E.; Santambrogio, L.; Nosotti, M.; Cataldo, I.; Sala, M.; Caldiera, S.; Bombardieri, E. Tumour markers CEA, NSE, SCC, TPA and CYFRA 21.1 in resectable non-small cell lung cancer. Anticancer Res. 1999, 19, 3613-3618.

31. Li, X.; Asmitananda, T.; Gao, L.; Seregni, E.; Santambrogio, L.; Nosotti, M.; Cataldo, I.; Sala, M.; Caldiera, S.; Bombardieri, E. Biomarkers in the lung cancer diagnosis: A clinical perspective. Neoplasma 2012, 59, 500-507.

32. Chiu, C.H.; Shih, Y.N.; Tsai, C.M.; Liou, J.L.; Chen, Y.M.; Perng, R.P. Serum tumor markers as predictors for survival in advanced non-small cell lung cancer patients treated with gefitinib. Lung Cancer 2007, 57, 213-221.

33. Ma, S.; Shen, L.; Qian, N.; Chen, K.The prognostic values of CA125, CA19.9, NSE, AND SCC for stage I NSCLC are limited. Cancer Biomark. 2011-2012, 10, 155-162.

34. Tomita, M.; Shimizu, T.; Ayabe, T.; Onitsuka, T. Maximum SUV on positron emission tomography and serum CEA level as prognostic factors after curative resection for non-small cell lung cancer. Asia Pac. J. Clin. Oncol. 2012, 8, 244-247.

35. Grunnet, M.; Sorensen, J.B. Carcinoembryonic antigen (CEA) as tumor marker in lung cancer. Lung Cancer 2012, 76, 138-143.

36. Cho, W.C. Potentially useful biomarkers for the diagnosis, treatment and prognosis of lung cancer. Biomed. Pharmacother. 2007, 61, 515-519.

(C) 2013 by the authors; licensee MDPI, Basel, Switzerland. This article is an open access article distributed under the terms and conditions of the Creative Commons Attribution license (http://creativecommons.org/licenses/by/3.0/). 